\title{
Correction: Sequencing of the MHC region defines HLA-DQA1 as the major genetic risk for seropositive rheumatoid arthritis in Han Chinese population
}

Guo J, Zhang T, Cao H, et al. Sequencing of the MHC region defines HLA-DQA1 as the major genetic risk for seropositive rheumatoid arthritis in Han Chinese population. Ann Rheum Dis 2019;78:773-80. doi: 10.1136/annrheumdis-2018-214725.

- In the text, all DR $\beta 1: 96$ hours should be DR $\beta 1: 96 \mathrm{H}$.

- The sentence on page 775, "followed by DQ $\alpha 1$ :160A $\left(p=6.25 \times 10^{-17}, \mathrm{OR}=2.27,95 \%\right.$ CI 1.87 to 2.75$)$ " should be "followed by DQ $\alpha 1: 160 \mathrm{~A}\left(\mathrm{p}=6.25 \times 10^{-17}, \mathrm{OR}=0.44,95 \%\right.$ CI 0.36 to 0.53$) "$.

- The sentences on page 776 ,

- "DR $\beta 1: 96$ hours also showed a significant association $\left(\mathrm{p}=6.27 \times 10^{-7}, \mathrm{OR}=1.59\right.$, $95 \%$ CI 1.33 to 1.91 )" should be "DR $\beta 1: 96 \mathrm{H}$ also showed a significant association $\left(\mathrm{p}=6.27 \times 10^{-7}, \mathrm{OR}=0.64,95 \%\right.$ CI 0.53 to 0.77$)$ ”.

- "Although DR $\beta 1: 96$ hours became the second independent signal $\left(p=2.80 \times 10^{-10}\right.$, $\mathrm{OR}=1.68,95 \% \mathrm{CI} 1.43$ to 1.97$)$ ) should be "although $\mathrm{DR} \beta 1: 96 \mathrm{H}$ became the second independent signal $\left(\mathrm{p}=2.80 \times 10^{-10}, \mathrm{OR}=0.58,95 \%\right.$ CI 0.49 to 0.68$)$ ”.

- "DR $\beta 1: 96$ hours and DR $\beta 1: 37 \mathrm{~N}$ showed similar independent effects (DR $\beta 1: 96$ hours: $p=4.90 \times 10^{-16}, \mathrm{OR}=1.64,95 \%$ CI 1.45 to $1.84 \ldots$ ” should be "DR $\beta 1: 96 \mathrm{H}$ and DR $\beta 1: 37 \mathrm{~N}$ showed similar independent effects $\left(\mathrm{DR} \beta 1: 96 \mathrm{H}: \mathrm{p}=4.90 \times 10^{-16}\right.$, $\mathrm{OR}=0.60$, $95 \%$ CI 0.54 to $0.68 \ldots$.

Figure 3 has been corrected. In the revised figure 3, the frequencies on $\mathrm{Y}$ axis have been presented according to original frequencies instead of the minor frequencies.

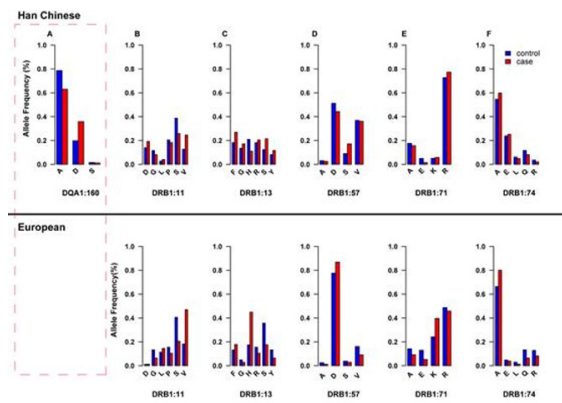

Figure 3 Comparison of individual amino acid frequencies within DQ $\alpha 1: 160$ and DR $\beta 1: 11,13,57,71$, and 74 in Han Chinese and European populations. The individual amino acid frequencies are plotted in healthy controls (blue) and cases (red). Upper panel shows the amino acid frequencies in Han Chinese population (the data derived from present study). Lower panel shows the amino acid frequencies in European population (the data cited from Raychaudhur's study ${ }^{6}$ ). (A) DQ $\alpha 1: 160 D$ and DQ $\alpha 1: 160 A$ are common amino acids in Han Chinese, but the two variants have not been detected in European population. Similar frequencies of amino acids were observed at DRß1 position 11(B), 13(C), 57(D), 71(E), and 74(F) between Han Chinese and European populations.

Supplementary tables 3-6 and 8 have been corrected. In these tables, a few frequencies have now been presented as original frequencies instead of the minor frequencies and the ORs have been revised accordingly.

\begin{tabular}{|c|c|c|c|c|c|c|}
\hline \multicolumn{2}{|c|}{ Supplementary Table 3} & \multicolumn{5}{|c|}{ Logistic regression analysis in discovery cohort, using gender as covariate } \\
\hline CHR & Marker & Case & Control & Non-reference amino-acid & OR $(95 \% \mathrm{Cl})$ & $P$ value \\
\hline 6 & DQA1:160:A & 0.62 & 0.79 & DQA1:160:A & 0.44 (0.36 to 0.53$)$ & $6.25 \mathrm{E}-17$ \\
\hline 6 & DQA1:34:E & 0.60 & 0.48 & DQA1:34:E & 1.66 (1.39 to 1.99$)$ & 7.46E-09 \\
\hline 6 & DRB1:31:F & 0.71 & 0.81 & DRB1:31:F & $0.58(0.47$ to 0.70$)$ & 8.77E-08 \\
\hline 6 & DRB1:10:Q & 0.70 & 0.60 & DRB1:10:Q & 1.58 (1.31 to 1.91$)$ & $9.14 \mathrm{E}-07$ \\
\hline
\end{tabular}


Supplementary Table 4 Stepwise conditional analysis on HLA-DQ $\alpha 1: 160 \mathrm{D}$ in discovery cohort using gender as covariate

\begin{tabular}{lllllll}
\hline CHR & Marker & Case & Control & Non-reference amino-acid & OR (95\% CI) & P value \\
\hline 6 & DRB1:96:H & 0.55 & 0.64 & DRB1:96:H & $0.64(0.53$ to 0.77) & $6.27 \mathrm{E}-07$ \\
\hline P value less than $1.0 \times 10^{-6}$ was considered as cut-off. & & & & & \\
\hline
\end{tabular}

Supplementary Table 5 Logistic regression analysis in validation cohort, using gender as covariate

\begin{tabular}{lllllll}
\hline CHR & Marker & Case & Control & Non-reference amino-acid & OR $(95 \%$ CI) & P value \\
\hline 6 & DQA1:160:A & 0.63 & 0.78 & DQA1:160:A & $0.47(0.40$ to 0.56$)$ & $4.18 \mathrm{E}-17$ \\
6 & DQA1:34:E & 0.60 & 0.47 & DQA1:34:E & $1.63(1.40$ to 1.89$)$ & $1.41 \mathrm{E}-10$ \\
6 & DRB1:96:H & 0.52 & 0.64 & DRB1:96:H & $0.59(0.50$ to 0.68$)$ & $4.06 \mathrm{E}-10$ \\
6 & DRB1:10:Q & 0.71 & 0.60 & DRB1:10:Q & $1.61(1.38$ to 1.87$)$ & $4.13 \mathrm{E}-09$ \\
\hline P value less than $5.0 \times 10^{-8}$ was considered as cut-off. & & & &
\end{tabular}

Supplementary Table 6 Stepwise conditional analysis on HLA-DQ $\alpha 1: 160 D$ in validation cohort, using gender as covariate

\begin{tabular}{lllllll}
\hline CHR & Marker & Case & Control & Non-reference amino-acid & OR $(95 \%$ Cl $)$ & P value \\
\hline 6 & DRB1:96:H & 0.52 & 0.64 & DRB1:96:H & $0.58(0.49$ to 0.68$)$ & $2.80 \mathrm{E}-10$ \\
6 & DRB1:74:A & 0.61 & 0.56 & DRB1:74:A & $1.59(1.35$ to 1.88$)$ & $5.26 \mathrm{E}-07$ \\
\hline P value less than $5.0 \times 10^{-8}$ was considered as cut-off. & & & &
\end{tabular}

Supplementary Table 8 Stepwise conditional analysis on HLA-DQ $\alpha 1: 160 D$ in combined cohort, using gender as covariate

\begin{tabular}{lllllll}
\hline CHR & Marker & Case & Control & Non-reference amino-acid & OR (95\% CI) & P value \\
\hline 6 & DRB1:96:H & 0.53 & 0.64 & DRB1:96:H & $0.60(0.54$ to 0.68$)$ & $4.90 \mathrm{E}-16$ \\
6 & DRB1:74:A & 0.60 & 0.55 & DRB1:74:A & $1.58(1.39$ to 1.78$)$ & $2.04 \mathrm{E}-12$ \\
\hline
\end{tabular}

$P$ value less than $5.0 \times 10^{-8}$ was considered as cut-off.

Case: frequencies of the Non-reference amino-acid in cases.

Control: frequencies of the Non-reference amino-acid in controls.

(c) Author(s) (or their employer(s)) 2020. No commercial re-use. See rights and permissions. Published by BMJ.

Ann Rheum Dis 2020;79:e76. doi:10.1136/annrheumdis-2018-214725corr1

A) Check for updates 